\title{
A Ti/Ti-Based-Metallic-Glass Interpenetrating Phase Composite with Remarkable Mutual Reinforcement Effect
}

\author{
J. Mu, ${ }^{1}$ Z. W. Zhu, ${ }^{2}$ H. F. Zhang, ${ }^{2}$ H. W. Zhang, ${ }^{2}$ H. M. Fu, ${ }^{2}$ \\ H. Li, ${ }^{2}$ A. M. Wang, ${ }^{2}$ and Z. Q. Hu ${ }^{2}$ \\ ${ }^{1}$ Key Laboratory for Anisotropy and Texture of Materials, Northeastern University, Shenyang 110004, China \\ ${ }^{2}$ Shenyang National Laboratory for Materials Science, Institute of Metal Research, Chinese Academy of Sciences, \\ 72 Wenhua Road, Shenyang 110016, China
}

Correspondence should be addressed to H. F. Zhang; hfzhang@imr.ac.cn

Received 21 February 2014; Accepted 22 April 2014; Published 14 May 2014

Academic Editor: Limei Xu

Copyright (C) 2014 J. Mu et al. This is an open access article distributed under the Creative Commons Attribution License, which permits unrestricted use, distribution, and reproduction in any medium, provided the original work is properly cited.

A Ti/Ti-based-metallic-glass interpenetrating phase composite (IPC) was prepared by infiltrating the $\mathrm{Ti}_{34 .} \mathrm{Zr}_{31.5} \mathrm{Ni}_{55} \mathrm{Cu}_{5} \mathrm{Be}_{23.7} \mathrm{melt}$ into the porous Ti skeleton. Porous Ti limits the shear band (SB) propagation and promotes the SB multiplication, leading to the improved ductility. Moreover, the interpenetrating phase structure shows a mutual reinforcement effect for both amorphous and crystalline phases, making IPC possess higher strength than that calculated by the models held for the conventional composites. This finding will suggest a new way for preparing composites with high strength and ductility.

Bulk metallic glass composites (BMGCs) have attracted lots of attention due to the combinations of strength and ductility [1-3]. The reinforcement is usually in the shape of particles [4-6], fibers [7, 8], and so forth. It is classified into the two types of ductile and brittle one by the nature. Recently, ductile crystalline inclusions have been proven to more effectively improve the plasticity of the composites [9-18]. For example, Zr- or Ti-based Be-bearing BMGCs containing bodycentered cubic (b.c.c.) dendrites exhibit more than 10\% plastic strain under tension as well as high processability, which causes lots of interests worldwide [9-13]. The introduction of high volume fraction dendrites with the low strength indeed improves the ductility but apparently reduces the strength of materials, which limits their practical utility to some extent. It is challenging to prepare the BMGC with high strength and plasticity.

In this letter, an idea of interpenetrating phase composite (IPC) [19-21] was applied, which is prepared by infiltrating the melt into the prefabricated porous skeleton, to overcome this aforementioned issue. Generally speaking, the skeleton is fabricated by powder consolidation so that it is easy to achieve the microstructure as desired. The volume fraction and pore size can be controlled. Accordingly, in the IPCs, each individual phase continuously extends in a 3D space to form a completely homogeneously interconnected network. Each amorphous unit in a nano- or microscale will present a strong size effect $[22,23]$, which leads to the IPC possessing higher strength. Meanwhile, good plasticity is obtained through the propagation limitation and multiplication of shear bands by the well-connected crystalline phase with a considerable volume fraction. As a result, the IPC containing amorphous phase will show high strength and ductility. Herein, we present a Ti/Ti-based-metallic-glass IPC, which exhibits the strength as high as $1740 \mathrm{MPa}$ and the ductility of $\sim 10 \%$.

Master ingots with nominal composition of $\mathrm{Ti}_{34.3} \mathrm{Zr}_{31.5} \mathrm{Ni}_{5.5} \mathrm{Cu}_{5} \mathrm{Be}_{23.7}$ (in atomic percentage) [24] were prepared by arc melting the mixture of the element metals in a Ti-getter high-purity argon atmosphere. Titanium skeleton (purity $\geq 99.9 \mathrm{wt} . \%$ ) with a porosity of $\sim 60 \%$ and pore size of $30 \sim 300 \mu \mathrm{m}$ was used as the infiltration skeleton. The composites were prepared by pressure assisted infiltrating the $\mathrm{Ti}_{34.3} \mathrm{Zr}_{31.5} \mathrm{Ni}_{5,5} \mathrm{Cu}_{5} \mathrm{Be}_{23.7}$ melt into the porous Ti skeleton at $1123 \mathrm{~K}$. The pressure and time in the infiltrating process were about $1 \mathrm{MPa}$ and $5 \mathrm{~min}$, respectively. The as-prepared samples were characterized with X-ray diffraction (XRD, Philips PW1050, $\mathrm{Cu}-\mathrm{K}_{\alpha}$ ), scanning 
electron microscope (SEM, Hitachi S3400N) coupled with energy dispersive spectrometer (EDS, Oxford), transmission electron microscope (TEM, JEOL 2010, $200 \mathrm{kV}$ ), and differential scanning calorimeter (DSC, Netzsch DSC 204 F). DSC measurements were performed in a flowing argon atmosphere at a heating rate of $40 \mathrm{~K} / \mathrm{min}$. Compression tests were conducted in an Instron 5582 universal testing machine at a strain rate of $5 \times 10^{-4} \mathrm{~s}^{-1}$ at room temperature. Fractured samples were observed using SEM and TEM.

Figure 1(a) shows the XRD patterns of the as-prepared composite. For comparison, the XRD patterns of porous $\mathrm{Ti}$ skeleton used in the present work are also displayed in Figure 1(a). It can be seen that the XRD patterns of the composite are comprised of the apparent Bragg peaks, some of which are identical to those of the porous Ti. It indicates that the porous $\mathrm{Ti}$ is retained in the composite, which is indexed as $\alpha$-Ti. Besides $\alpha$-Ti, the other weak peaks are probably identified as $\beta-\mathrm{Ti}$, of which the intensity shows that its volume fraction is quite low. Whether the amorphous phase forms or not is difficult to be recognized from the XRD patterns in Figure 1(a), because the Bragg peaks corresponding to the crystalline phases are very strong.

The existence of amorphous phase in the as-prepared sample is demonstrated by DSC measurements, as shown in Figure 1(b). DSC curves of the composite exhibit an obvious glass transition and crystallization. The specimens cut from the top and bottom of the as-prepared samples were both examined. In comparison with the DSC curve of monolithic $\mathrm{BMG}$, it is found out that the composite has similar thermal characteristic temperatures as those of monolithic BMG. It is implied that the composition of the amorphous matrix in this composite is not changed largely, which will not ruin the glass forming ability of $\mathrm{Ti}_{34.3} \mathrm{Zr}_{31.5} \mathrm{Ni}_{5.5} \mathrm{Cu}_{5} \mathrm{Be}_{23.7}$ (at.\%) alloy. [24] That is to say, high glass forming ability of the master alloy will ensure that the composite may be prepared in large sizes. In the present work, the sample of $10 \times 40 \times 60 \mathrm{~mm}$ was prepared (not shown here).

The phase distribution morphology of the as-prepared composite was observed, as shown in Figures 1(c) and 1(d). From the SEM images in Figure 1(c), it can be found out that all the pores of Ti skeleton are filled with the Ti-based metallic glass. No visible void can be seen on the interface. Careful examination of the interface between $\alpha$-Ti and the amorphous phases shows the presence of a continuous transition layer with a thickness of $\sim 8 \mu \mathrm{m}$, as shown in Figure 1(d). In the amorphous phase, some dendrites with the size $<5 \mu \mathrm{m}$ precipitated, as marked by the ellipses in Figure $1(\mathrm{~d})$. The EDS analysis indicates that they have the similar composition, which is mainly composed of $\mathrm{Ti}$ and $\mathrm{Zr}$, of which the contents are 85.9 at.\% and 12.6 at.\%, respectively. $\mathrm{Zr}$ is considered as an element stabilizing $\beta$-Ti solution [25]. Accordingly, it is probable that the transition layer and the precipitated dendrites should correspond to $\beta$-Ti as indicated by XRD measurements (Figure 1(a)), which is further clarified by TEM observations. Figure 1(e) shows the bright field image of TEM for the composite, clearly showing that the dendrite is embedded in the featherless matrix. The corresponding selected area electron diffraction (SAED) patterns are inset with Figure 1(e), illustrating that the amorphous and bodycentered cubic (b.c.c.) phase are for the matrix and dendrite, respectively. The interface between both the phases is shown in high resolution in Figure 1(f). It confirms that there are not any reaction products that are observed and both the phases are atomically bonded.

Mechanical properties of the as-prepared composite were measured by quasistatic compression tests. The specimens of $4 \times 4 \times 8 \mathrm{~mm}$ were used. For a comparison, the compressive stress-strain curves of the porous $\mathrm{Ti}$ and monolithic BMG were also displayed in Figure 2(a). The porous Ti exhibits an extremely low strength and hardly fails under compressive loading. On the contrary, the monolithic BMG fractured without any plastic deformation under loading. The fracture strength is as high as about $1830 \mathrm{MPa}$. It is clear to show that the composite possesses the advantages of both materials as expected, including high strength and considerable plasticity. The yield strength, plasticity, and fracture strength are approximately $1400 \mathrm{MPa}, 10 \%$, and $1740 \mathrm{MPa}$ for the present composite, respectively.

As reported by the previous works $[6,7,26]$, the yield strength of BMGCs containing the particles and fibers of the relatively low volume fraction (i.e., <30\%) still follows the rule of mixture (ROM), which is expressed as follows:

$$
\sigma^{c}=f_{\alpha} \sigma^{\alpha}+f_{\beta} \sigma^{\beta}
$$

where $f$ and $\sigma$ are the volume fraction and the yield strength of the constituent phases and subscript/superscript $\alpha$ and $\beta$ refer to the pure titanium and the BMG in the present study, respectively.

For the volume fraction of the crystalline phase more than $50 \%$ of the load-bearing model is applied to calculate the yield strength of the composite as follows [27]:

$$
\sigma^{c}=\left(1+0.5 f_{\beta}\right) \sigma^{\alpha}
$$

Suppose that the amorphous/crystalline IPCs are the same as the conventional BMGCs and the strength is modeled as a function of volume fraction for $\mathrm{Ti} / \mathrm{Ti}$-based-metallic-glass IPCs, as shown in Figure 2(b). The mechanical parameters of the constituent phases are listed in Table $1[24,25]$. Between those two cases, the percolation theory is applied $[26,28]$ as schematically illustrated by the solid line in Figure 2(b).

Apparently, it is easy to find out that the yield strength of the current composite is higher than the value calculated by about $30 \%$, as shown in Figure 2(b). That is to say, each phase in the present composites yields at the higher stress under loading. It is believed that the enhancement effect arises from the present interpenetrating phase structure. As aforementioned, the composite is made by infiltrating $\mathrm{Ti}^{-}$ based metallic melt into the porous $\mathrm{Ti}$ skeleton so that each phase can exhibit a 3D network structure (Figure 1(c)). Microstructurally, each local unit of one phase is surrounded by the units belonging to the other phases. A sleeve-like confinement may mutually take place for each other under loading $[20,21]$, which makes the phases in the composites more difficult to plastically deform. It is apparently in favor of the enhancement of the yield strength for the present 


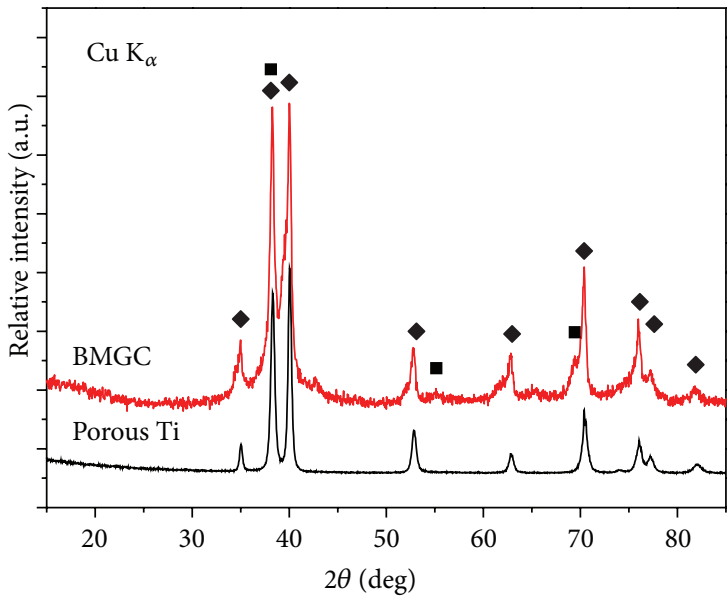

- $\alpha-\mathrm{Ti}$

- $\beta-\mathrm{Ti}$

(a)

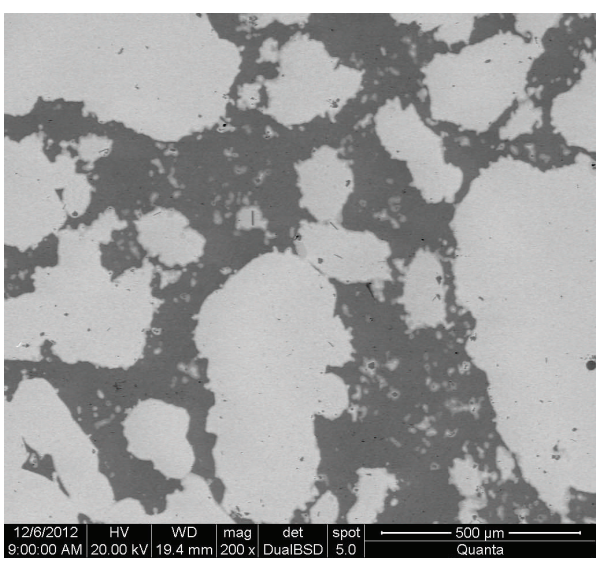

(c)

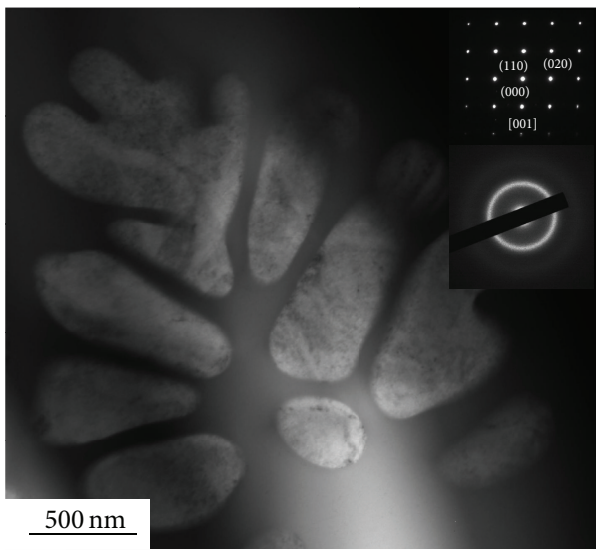

(e)

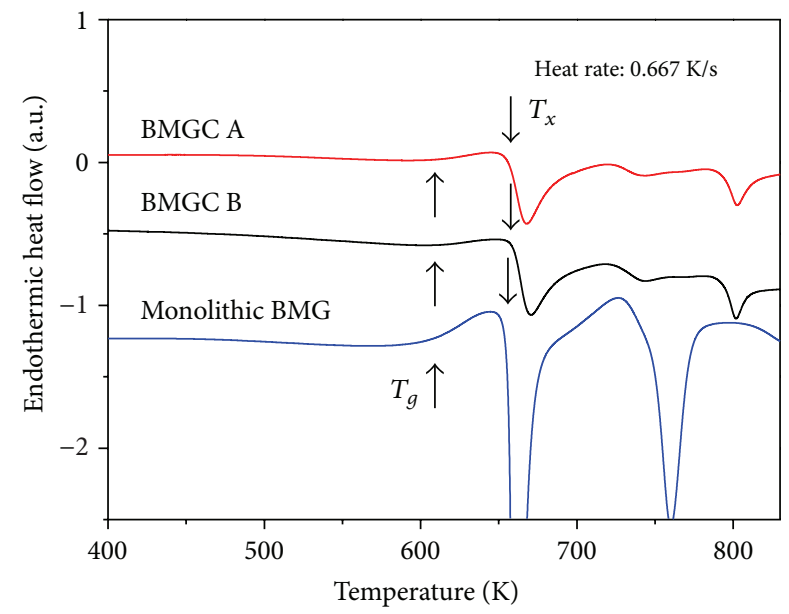

(b)

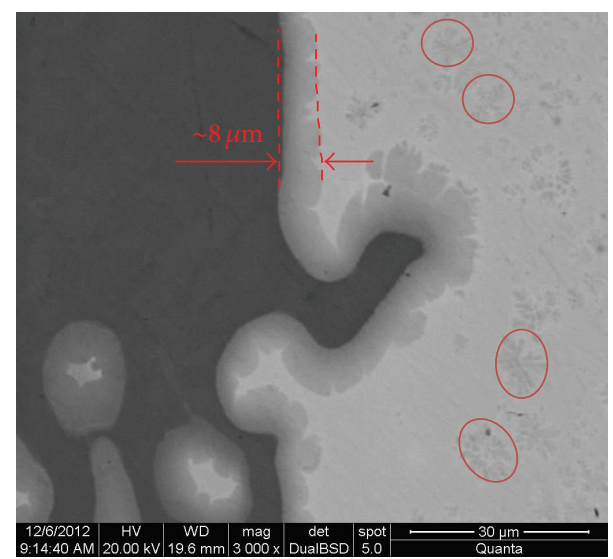

(d)

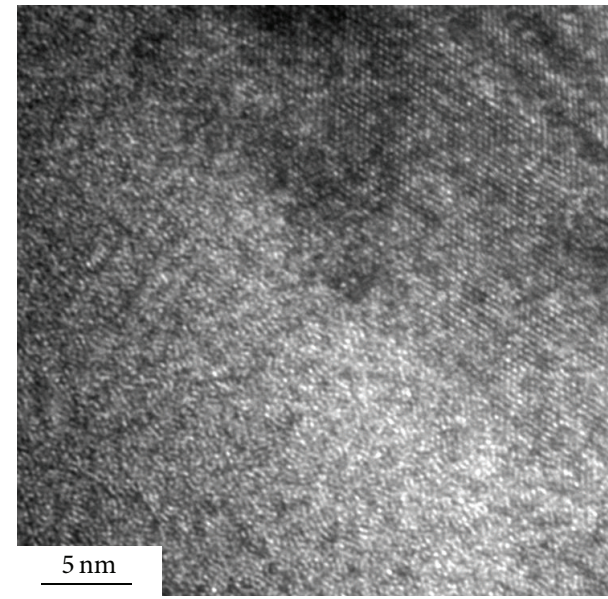

(f)

FIGURE 1: Structural characterizations of Ti/Ti-based-metallic-glass IPC. (a) XRD patterns of the composites and Ti skeleton. (b) DSC curves of the composites and monolithic BMG. (c) and (d) SEM micrographs. (e) and (f) TEM micrographs of IPC. 


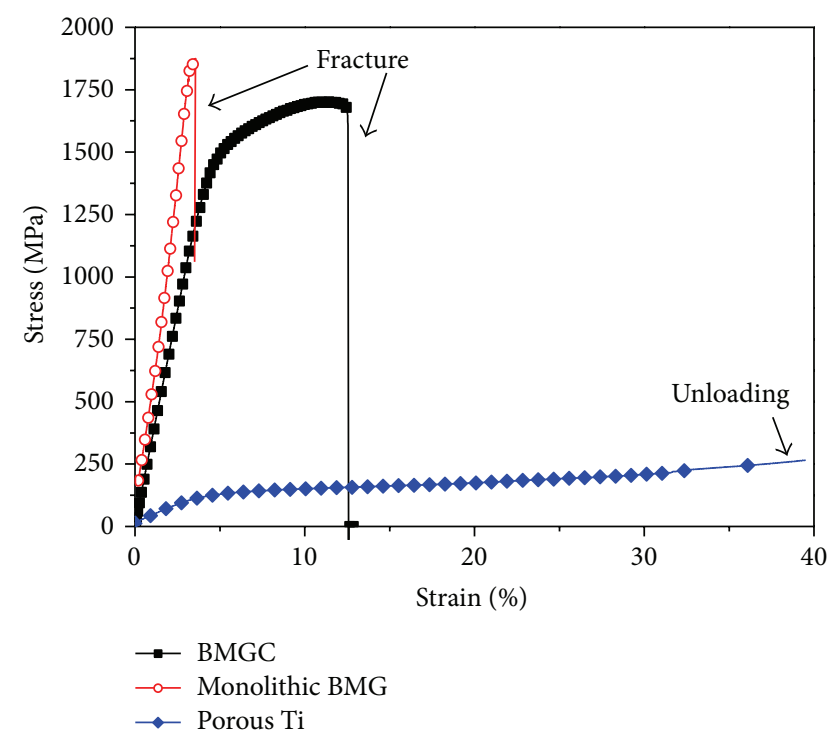

(a)

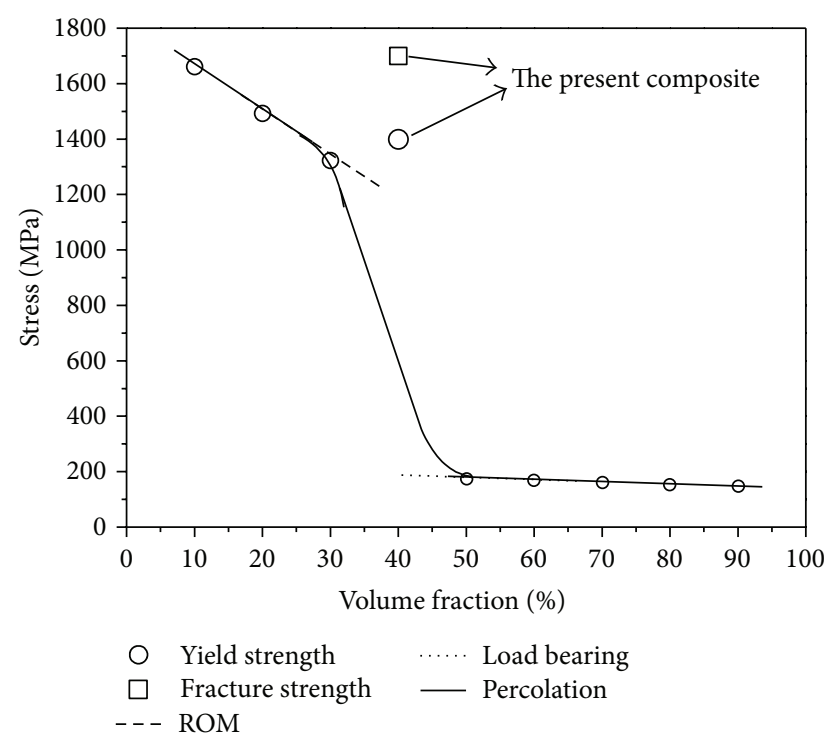

(b)

Figure 2: (a) Stress-strain curves of the monolithic BMG, porous Ti, and IPC and (b) comparison of experimental and calculated values of yield and fracture strength as a function of volume fraction for IPC.

TABLE 1: Density $(\rho)$, Young modulus $(E)$, shear modulus $(G)$, yield strength $\left(\sigma_{y}\right)$, and fracture strength $\left(\sigma_{f}\right)$ of $\alpha$-Ti and monolithic BMG.

\begin{tabular}{lccccc}
\hline & $\rho\left(\mathrm{g} / \mathrm{cm}^{3}\right)$ & $E(\mathrm{GPa})$ & $G(\mathrm{GPa})$ & $\sigma_{y}(\mathrm{MPa})$ & $140^{*}$ \\
\hline$\alpha-\mathrm{Ti}$ & 4.51 & 115 & 44 & $\sigma_{f}(\mathrm{MPa})$ \\
$\mathrm{BMG}$ & 5.54 & 97.8 & 36.1 & 1830 & $235^{*}$ \\
\hline
\end{tabular}

Note. ${ }^{*}$ The data are measured in tension [25].

composite. On the other hand, the size effect of glassy phase should be taken into account. Different from the composites containing the reinforcement particles and fibers where the glassy phase serves as the matrix, the glassy phase is one constituent in the present composite which is hard to be defined as the matrix or the reinforcement. And the local glassy phase units have the size of less than $300 \mu \mathrm{m}$, some of which are on a nano- or microscale. Recent studies show that metallic glasses have a strong size effect on the strength [23]. The yield strength of $\mathrm{Zr}$-Ti-Co-Be metallic glass reaches $2.25 \mathrm{GPa}$ when the specimen size reduces to $100 \mathrm{~nm}$ [23]. From this view of aspect, the confined units of the smaller size will produce the stronger enhancement effect. These results show the presence of remarkable mutual reinforcement effect for the constituent phases in the IPC, which results in the higher strength as shown in Figure 2(b).

The interpenetrating structure simultaneously improves the plasticity. As pointed in the previous study, the introduction of ductile phase into the BMG matrix tunes the stress state in the materials, [15] which inhibits the rapid propagation of shear bands and produces the multiple shear bands. A similar mechanism takes place in the present composite. The lateral surface of the fractured specimens was observed by SEM, as shown in Figure 3(a). Multiple shear bands are clearly seen in the glassy phase. It is of no doubt that the plastic deformation firstly occurs in Ti skeleton due to its relatively low yield strength. Abundant slip bands can be seen in the Ti skeleton as shown in the inset of Figure 3(a). The transition layer of $\beta$-Ti solution is good for the progressive deformation because it is harder than the pure Ti and softer than BMG. It will harmonize the deformation behaviors of local $\mathrm{Ti}$ and amorphous units. It is confirmed by the number density of slip bands or shear bands reducing from $\mathrm{Ti}$ skeleton to the glassy phase in the inset of Figure 3(a). Once the shear band initiates, the propagation will be inhibited by the crystalline phases. Figure 3(b) shows the dendrite arresting the shear band. This behavior makes the specimens avoid the sudden fracture due to the rapid propagation of shear bands. Shear band multiplication distributes the plastic strain, improving the plasticity.

To conclude, the present Ti/Ti-based-metallic-glass IPC exhibits advantageous properties. The sleeve-like confinement effect and size effect presented by the current continuous structure in the 3D space contribute to not only high plasticity but also high strength. It is implied that the crystalline/amorphous IPC will be served as a new way of producing BMGCs with good plasticity combined with high strength, which will promote the practical utility of BMGCs.

\section{Conflict of Interests}

The authors declare that there is no conflict of interests regarding the publication of this paper. 


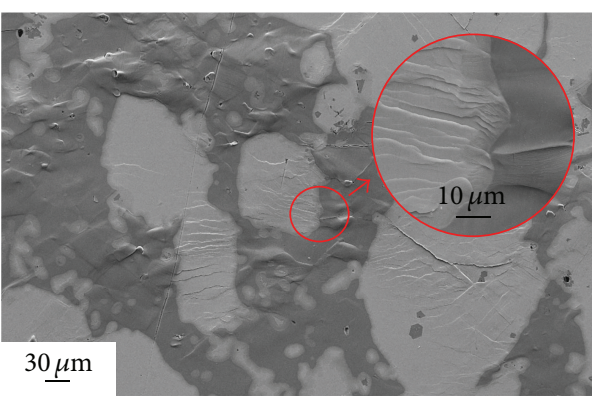

(a)

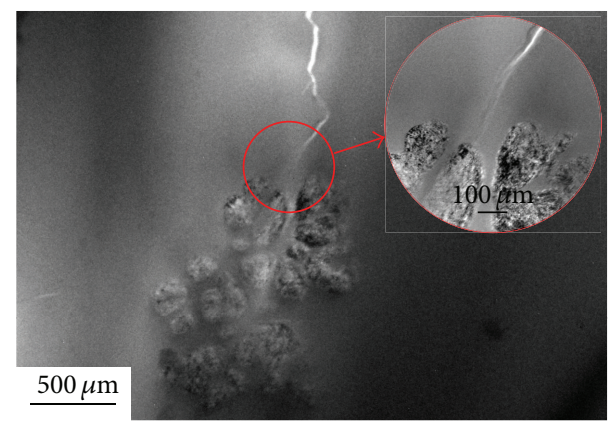

(b)

FIGURE 3: (a) SEM micrographs of the lateral surface of fractured sample showing that the crystalline phase restrains the shear band motion and gives rise to multiple shear bands in the glassy phase; (b) TEM micrographs of deformed samples showing that the precipitated crystalline phase inhibits the microcrack propagation.

\section{Acknowledgments}

The authors acknowledge the financial support from the One Hundred Person Project of the Chinese Academy of Sciences, National Basic Research Program of China (no. 2011CB606301), and the National Natural Science Foundation of China (nos. 51001097 and 51301034).

\section{References}

[1] H. Choi-Yim, W. L. Johnson, R. D. Conner, R. B. Dandliker, and W. L. Johnson, "Bulk metallic glass matrix composites," Applied Physics Letters, vol. 71, pp. 3808-3810, 1997.

[2] J. Eckert, J. Das, S. Pauly, and C. Duhamel, "Mechanical properties of bulk metallic glasses and composites," Journal of Materials Research, vol. 22, no. 2, pp. 285-301, 2007.

[3] T. C. Hufnagel, C. Fan, R. T. Ott, J. Li, and S. Brennan, "Controlling shear band behavior in metallic glasses through microstructural design," Intermetallics, vol. 10, no. 11-12, pp. 1163-1166, 2002.

[4] F. Szuecs, C. P. Kim, and W. L. Johnson, "Mechanical properties of $\mathrm{Zr}_{56.2} \mathrm{Ti}_{13.8} \mathrm{Nb}_{5.0} \mathrm{Cu}_{6.9} \mathrm{Ni}_{5.6} \mathrm{Be}_{12.5}$ ductile phase reinforced bulk metallic glass composite," Acta Materialia, vol. 49, no. 9, pp. 1507-1513, 2001.

[5] H. Kato, T. Hirano, A. Matsuo, Y. Kawamura, and A. Inoue, "High strength and good ductility of $\mathrm{Zr}_{55} \mathrm{AI}_{10} \mathrm{Ni}_{5} \mathrm{Cu}_{30}$ bulk glass containing ZRC particles," Scripta Materialia, vol. 43, no. 6, pp. 503-507, 2000.

[6] H. Choi-Yim, R. Busch, U. Köster, and W. L. Johnson, "Synthesis and characterization of particulate reinforced $\mathrm{Zr}_{57} \mathrm{Nb}_{5} \mathrm{AI}_{10} \mathrm{Cu}_{15.4} \mathrm{Ni}_{12.6}$ bulk metallic glass composites," Acta Materialia, vol. 47, no. 8, pp. 2455-2462, 1999.

[7] R. D. Conner, R. B. Dandliker, and W. L. Johnson, "Mechanical properties of tungsten and steel fiber reinforced $\mathrm{Zr}_{41.25} \mathrm{Ti}_{13.75} \mathrm{Cu}_{12.5} \mathrm{Ni}_{10} \mathrm{Be}_{22.5}$ metallic glass matrix composites," Acta Materialia, vol. 46, no. 17, pp. 6089-6102, 1998.

[8] K. Q. Qiu, A. M. Wang, H. F. Zhang, B. Z. Ding, and Z. Q. $\mathrm{Hu}$, "Mechanical properties of tungsten fiber reinforced ZrAlNiCuSi metallic glass matrix composite," Intermetallics, vol. 10, no. 11-12, pp. 1283-1288, 2002.

[9] D. C. Hofmann, J.-Y. Suh, A. Wiest et al., "Designing metallic glass matrix composites with high toughness and tensile ductility," Nature, vol. 451, no. 7182, pp. 1085-1089, 2008.
[10] D. C. Hofmann, J.-Y. Suh, A. Wiest, M.-L. Lind, M. D. Demetriou, and W. L. Johnson, "Development of tough, lowdensity titanium-based bulk metallic glass matrix composites with tensile ductility," Proceedings of the National Academy of Sciences of the United States of America, vol. 105, no. 51, pp. 20136-20140, 2008.

[11] C. P. Kim, Y. S. Oh, S. Lee, and N. J. Kim, "Realization of high tensile ductility in a bulk metallic glass composite by the utilization of deformation-induced martensitic transformation," Scripta Materialia, vol. 65, no. 4, pp. 304-307, 2011.

[12] J. W. Qiao, S. Wang, Y. Zhang, P. K. Liaw, and G. L. Chen, "Large plasticity and tensile necking of Zr-based bulk-metallic-glassmatrix composites synthesized by the Bridgman solidification," Applied Physics Letters, vol. 94, no. 15, 2009.

[13] G. Chen, J. L. Cheng, and C. T. Liu, "Large-sized Zr-based bulkmetallic-glass composite with enhanced tensile properties," Intermetallics, vol. 28, pp. 25-33, 2012.

[14] U. Kühn, J. Eckert, N. Mattern, and L. Schultz, "ZrNbCuNiAl bulk metallic glass matrix composites containing dendritic bcc phase precipitates," Applied Physics Letters, vol. 80, no. 14, pp. 2478-2480, 2002.

[15] Z. Zhu, H. Zhang, Z. Hu, W. Zhang, and A. Inoue, "Taparticulate reinforced Zr-based bulk metallic glass matrix composite with tensile plasticity," Scripta Materialia, vol. 62, no. 5, pp. 278-281, 2010.

[16] C. Fan, R. T. Ott, and T. C. Hufnagel, "Metallic glass matrix composite with precipitated ductile reinforcement," Applied Physics Letters, vol. 81, no. 6, pp. 1020-1022, 2002.

[17] Y. Wu, H. Wang, H. H. Wu et al., "Formation of Cu-Zr-Al bulk metallic glass composites with improved tensile properties," Acta Materialia, vol. 59, no. 8, pp. 2928-2936, 2011.

[18] M. L. Lee, Y. Li, and C. A. Schuh, "Effect of a controlled volume fraction of dendritic phases on tensile and compressive ductility in La-based metallic glass matrix composites," Acta Materialia, vol. 52, no. 14, pp. 4121-4131, 2004.

[19] D. R. Clarke, "Interpenetrating phase composites," Journal of the American Ceramic Society, vol. 75, no. 4, pp. 739-759, 1992.

[20] H. F. Zhang, A. M. Wang, H. Li et al., "Quasi-static compressive property of metallic glass/porous tungsten bi-continuous phase composite," Journal of Materials Research, vol. 21, no. 6, pp. 1351$1354,2006$.

[21] Y. Sun, H. F. Zhang, A. M. Wang et al., "Mg-based metallic glass/titanium interpenetrating phase composite with high 
mechanical performance," Applied Physics Letters, vol. 95, no. 17, pp. 171910-171913, 2009.

[22] C. J. Lee, J. C. Huang, and T. G. Nieh, "Sample size effect and microcompression of $\mathrm{Mg}_{65} \mathrm{Cu}_{25} \mathrm{Gd}_{10}$ metallic glass," Applied Physics Letters, vol. 91, no. 16, 2007.

[23] D. Jang and J. R. Greer, "Transition from a strong-yet-brittle to a stronger-and-ductile state by size reduction of metallic glasses," Nature Materials, vol. 9, pp. 215-219, 2010.

[24] M. Q. Tang, H. F. Zhang, Z. W. Zhu et al., "TiZr-base bulk metallic glass with over $50 \mathrm{~mm}$ in diameter," Journal of Materials Science \& Technology, vol. 26, no. 6, pp. 481-486, 2010.

[25] C. Leyens and M. Peters, Titanium and Titanium Alloys, Wiley Online Library, 2003.

[26] S. Pauly, G. Liu, G. Wang et al., "Modeling deformation behavior of $\mathrm{Cu}-\mathrm{Zr}-\mathrm{Al}$ bulk metallic glass matrix composites," Applied Physics Letters, vol. 95, no. 10, pp. 101906-101906-3, 2009.

[27] V. C. Nardone and K. M. Prewo, "On the strength of discontinuous silicon carbide reinforced aluminum composites," Scripta Metallurgica, vol. 20, no. 1, pp. 43-48, 1986.

[28] X. L. Fu, Y. Li, and C. A. Schuh, "Mechanical properties of metallic glass matrix composites: effects of reinforcement character and connectivity," Scripta Materialia, vol. 56, no. 7, pp. 617-620, 2007. 

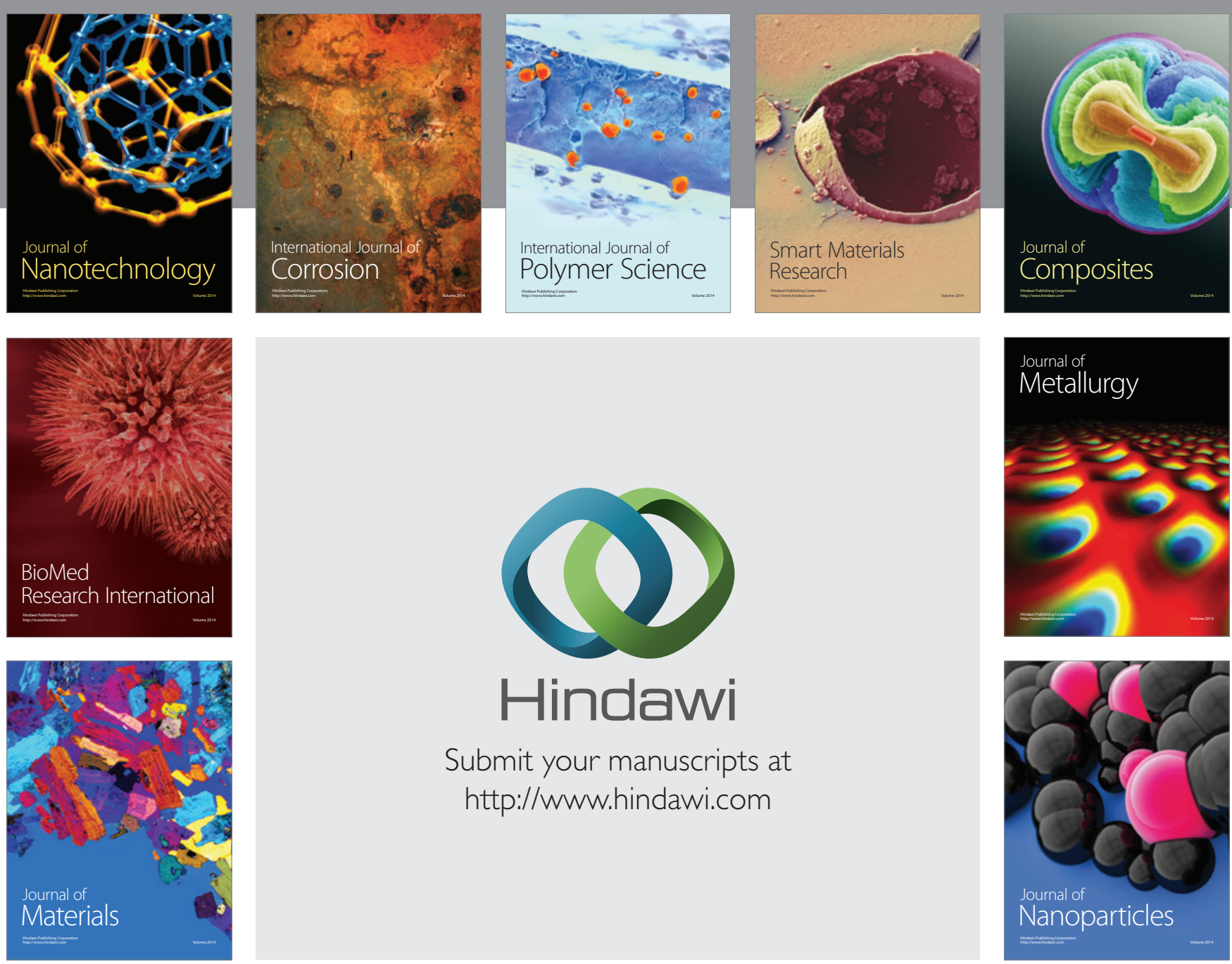

Submit your manuscripts at http://www.hindawi.com
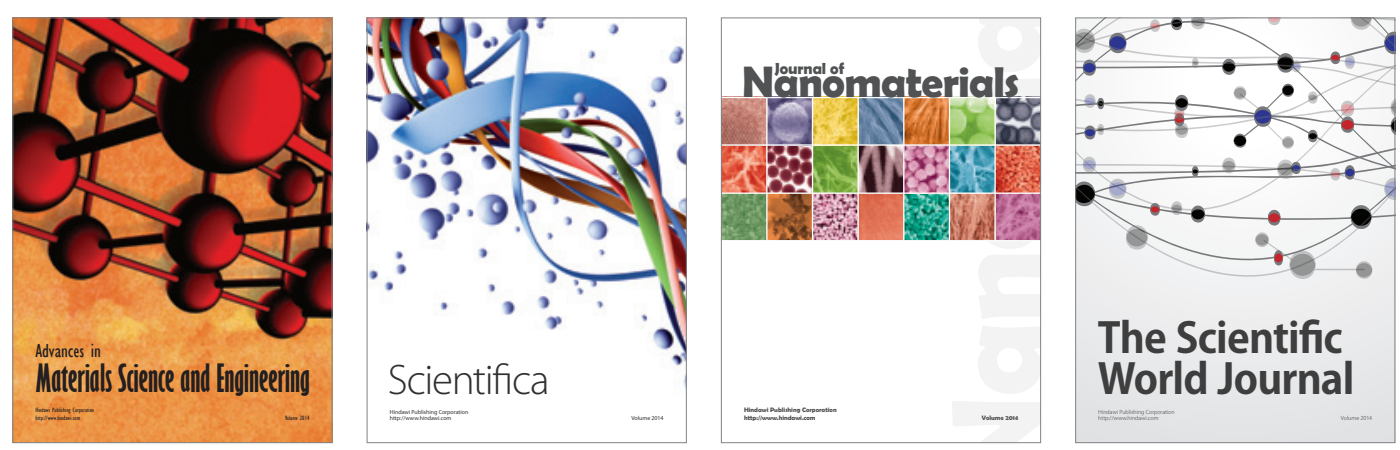

\section{The Scientific World Journal}
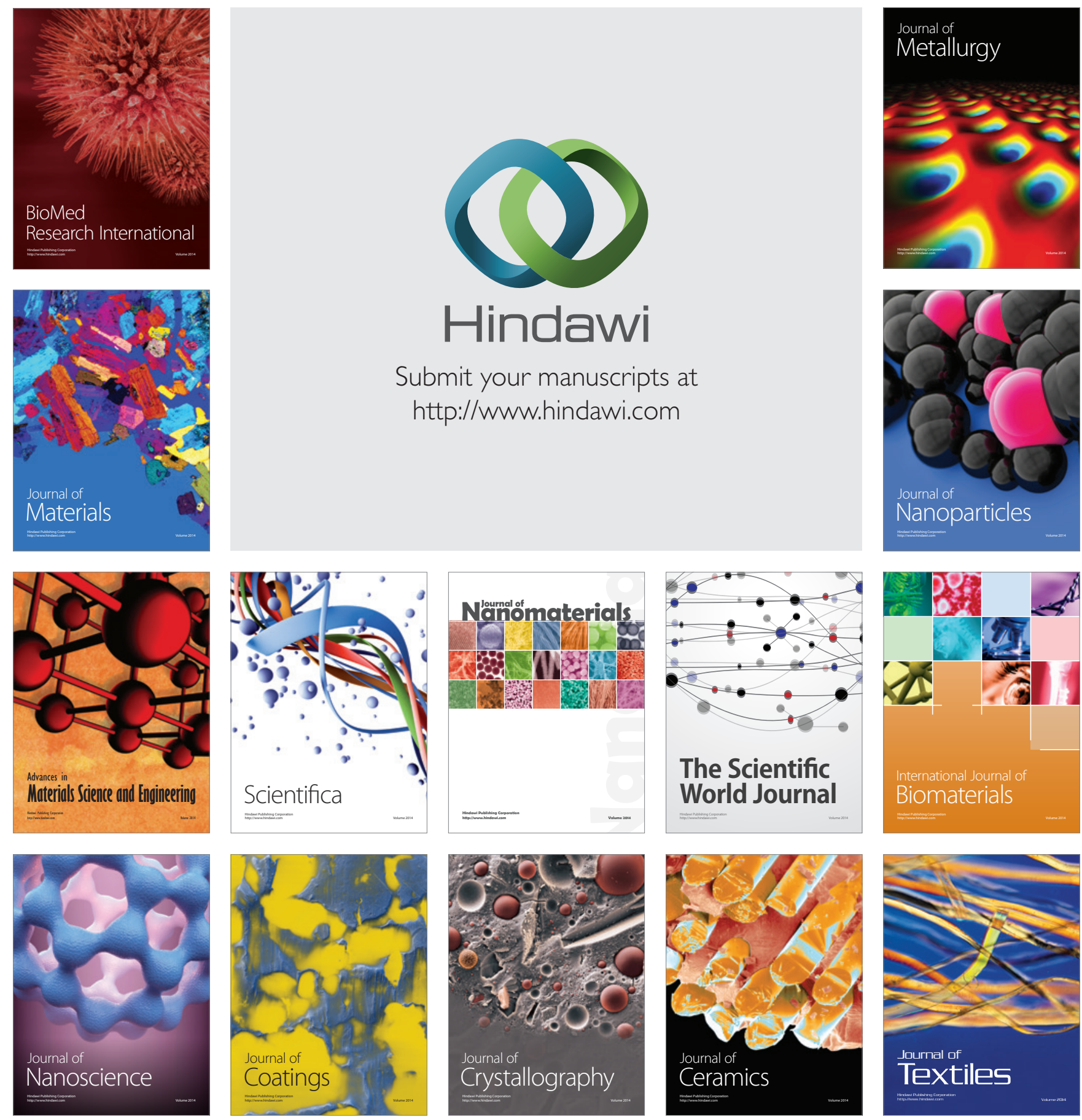